\title{
ASENTAMIENTO DE LA POBLACION Y ORDENAMIENTO JURIDICO GALLEGO
}

\author{
POR \\ José LUIS MEILÁN GIL \\ Catedrático de Derecho Administrativo \\ $y$ \\ JAIME F. RODRÍGUEZ-ARANA \\ Titular de Derecho Administrativo
}

SUMARIO: I. La ley de adaptación de la del Suelo a Galicia: orientación general.-II. El núcleo de población rural.-III. El núcleo de población en la legislación sectorial.-IV. Las limitaciones de la propiedad en las carreteras no estatales.

\section{LA LEY DE ADAPTACION DE LA DEL SUELO A GALICIA: ORIENTACION GENERAL}

Varias leyes de Galicia recogen las peculiaridades derivadas del asentamiento de la población (1). En primer término, la Ley 11/1985, de 2 de agosto, de adaptación de la del Suelo a Galicia («Diario Oficial de Galicia» de 29 de agosto). Su exposición de motivos no deja lugar a dudas acerca de la influencia decisiva del asentamiento de la población en una regulación adecuada del urbanismo, fundamentalmente por lo que se refiere al medio rural, llegándose a afirmar equívocamente que «a nosa realidade urbanística sexa atípica».

Desde su artículo $10^{\circ}$ la ley sienta con claridad que los Planes Generales y Normas Subsidiarias municipales clasificarán el suelo "tendo en conta as peculiares características dos asentamentos da poboación en Galicia, a súa organización parroquial e estructura comarcaly.

Ha de decirse, sin embargo, que pese a esa referencia fundamental a la estructura comarcal, que se reitera en el apartado 2 del

(1) En esa realidad tiene su fundamento el precepto contenido en el artículo 46.1.d del EG, que recoge uno de los criterios para mejorar la participación de la Comunidad Autónoma en los ingresos del Estado: «Relación entre los índices de déficit en servicios sociales en infraestructuras que afectan al territorio de la Comunidad y al conjunto del Estado.n A la misma razón obedece la extensión que realizó el Decreto $61 / 1960$, de 14 de enero, y el artículo 86 de la Ley de Expropiación Forzosa, sobre traslado de poblaciones, entendiéndolo referido no sólo estrictamente a las entidades locales menores, en él expresamente mencionadas, sino también a los núcleos separados de población, como parroquias, lugares, aldeas... Cfr. STS de 10 de noviembre de 1980 (Az. 4169). 
mismo artículo, la ley ignora prácticamente ese presupuesto a lo largo de su articulado. La explicación hay que encontrarla en la ausencia del planteamiento general de la organización del territorio en relación con el régimen jurídico de las entidades locales. Es precisamente en esa dimensión territorial donde puede abordarse un desarrollo urbanístico equilibrado, que supere la dicotomía campo-ciudad, como ha sucedido en las experiencias comparadas descritas, y para lo que Galicia ofrece unas características óptimas.

La abundancia de núcleos de población dispersos en el medio rural justifica la atención preferente que se otorga a ellos en la citada Ley $11 / 1985$, que por constituir su aspecto más relevante y característico será aquí de predominante atención.

Ese «predominio» rural conduce a corregir lo que es una deficiencia de orientación de la ley del Suelo estatal, tanto en su versión de 1956 como en la de 1975. Nos referimos a su visión preponderantemente urbana, volcada en la procura de suelo urbano para construcción de viviendas. Con esa óptica, el suelo no urbanizable, pese a la corrección ya introducida en la ley de 1975 (art. 80.2), tiende a configurarse de un modo residual, como no urbano o apto para ser urbanizado, más que por la vocación específica del mismo (2).

La identificación, más o menos consciente, entre suelo no urbanizable y el anterior suelo rústico es particularmente perniciosa para Galicia, condenando al medio rural a una calidad de vida inferior. Desde ese punto de vista resulta encomiable el instrumento de planeamiento que se recoge en la ley para facilitar la urbanización de «núcleos rurales tradicionales» según su terminología: los Planes de Mejora del Medio.

El núcleo de población rural tiene, por ello, una especial importancia en la ley. Su regulación específica era de todo punto necesaria, ya que la aplicación de la ley estatal del Suelo se reveló completamente inadecuada.

\section{EL NUCLEO DE POBLACION RURAL (3)}

Según el artículo 12.3:

«Terán o carácter de núcleo rural existentes aquelas áreas do territorio que, por existir agrupación de viviendas

(2) Además de lo manifestado en la exposición de motivos, el artículo 12.3 in fine incluye entre los «parámetros definitorios de núcleo rural... análogas».

(3) Cfr. M. B. BLANQUER PRATS: "Las bases fundamentales del núcleo de población», en $R D U$, marzo-abril, 1981. 
e xurdir relacións propias da vida comunitaria que as convertan nun asentamento poboacional singularizado, diferenciado e identificable, o Plan ou as Normas definan como tales, tendo en conta, ó menos, os prámetros de número e densidade de vivendas e distancia entre edificacións. Así mesmo dividiranse, segundo as súas características, en tradicionais e de recente formación.»

Debido al carácter realista que la reforma de la ley estatal del Suelo de 1975 acentuó para definir el suelo urbano [art. 78, a, LS, y 21 del Reglamento de Planeamiento (RP)], es fácil concluir que no pocos lugares de Galicia situados en el ámbito rural no cumplen con las notas exigidas para la definición de suelo urbano: Ni por la vía del apartado a) del artículo 21 del RP por carecer de los servicios citados allí ni -lo que aquí es sintomático- por la del apartado b) («ordenación consolidada concebida normalmente como edificaciones adosadas») por la proverbial diseminación de la población. Una lógica estricta lleva a calificar como suelo no urbanizable a esos espacios rurales en donde vive la población campesina.

Dejando el análisis de la concepción que subyace en esa -subconsciente 0 inconsciente- diferenciación ciudad-campo como dos modos de vida de desigual calidad (4), resulta que esa calificación lleva consigo la limitación que, en cuanto a edificación, señala la legislación del suelo. Concretamente la posibilidad de construir en ese suelo «edificios aislados destinados a vivienda familiar» queda condicionada a que en los lugares correspondientes "no exista posibilidad de formación de un núcleo de población» (art. 86 LS, en relación con el 85.2, 1. ${ }^{a}$ LS, y arts. 45 y 44 del Reglamento de Gestión Urbanística).

Del juego de ambos preceptos interpretados mecánicamente podría concluirse una extensión desmesurada y notoriamente injusta: De un lado, no existirían los requisitos necesarios para la calificación de suelo urbano y de otro podría levantarse el obstáculo del núcleo de población. El fin de la norma - de las limitaciones reseñadas- que es bien plausible y a que trata de evitar fraudes de ley transformando espúreamente suelo no urbanizable en urbano (5) produciría un resultado injusto y discriminador.

El concepto de «núcleo de población» es ciertamente un concepto jurídico indeterminado, pero la realidad a que responde no es uniforme ni en el tiempo ni en el territorio en que se pretenda

(4) Justamente eliminar esa dicotomía fue uno de los objetivos de la reforma del sistema local inglés iniciada con el Informe Radcliffe-Maud. Vid. J. L. MEILÁN GIL: "La cuestión regional», en Estudios en honor de S. Royo Villanova, Madrid, 1975.

(5) Cfr. ad exemplum, STS. de 25 de marzo de 1982 (Az. 2342), sobre un supuesto ocurrido en Galicia. 
identificar. Depende de la concepción que de la convivencia se tenga, del modo de asentamiento de la población que proporciona uno de los rasgos característicos de la identidad de una sociedad. Por eso, a nuestro entender acertadamente, en algún fallo judicial, se ha subrayado la conveniencia de conjugar aquella finalidad limitadora de las normas de referencia:

"Con las peculiaridades demográficas de la región donde se pretende edificar, en este caso la región asturiana donde la población se encuentra muy diseminada, ocupando edificios próximos, pero aislados» (6).

Una interpretación de los citados preceptos a la luz del artículo 2 del EAG permitía una aplicación no forzada de lo que se entiende por suelo urbano -con sus cargas- y una utilización flexible de las limitaciones que pesan sobre el suelo no urbanizable, entre tanto la Comunidad Autónoma no hubiese hecho de su potestad legislativa sobre la materia.

La citada ley autonómica 11/1985, de 22 de agosto, ha abordado el problema dedicando un capítulo, el III, al suelo y a los núcleos rurales, distinguiendo las clases de suelo legales en los núcleos rurales de carácter tradicional o de reciente formación y previendo la figura, ya citada, de un Plan especial de Mejora del Medio.

Por lo que se refiere al punto en cuestión, la ley «corta por lo sano" y dispensa de la obligación de justificar la imposibilidad de formación del núcleo:

«A autorización de edificacións e instalacións no solo non urbanizable dos núcleos rurais tradicionais non necesitará a xustificación de imposibilidade de formación do núcleo» (art. 21.2).

A superar las consecuencias de la concatenación medio rural-no urbanizable va dirigida también la posibilidad de definir los sistemas generales determinantes de la estructura general del territorio independientemente de la clasificación del suelo (art. 3.1).

\section{EL NUCLEO DE POBLACION EN LA LEGISLACION SECTORIAL}

El carácter diseminado de la población en Galicia obliga a interpretar de una manera apropiada a esa realidad el concepto de núcleo de población utilizado en diferentes normas.

(6) Sentencia de 22 de febrero de 1983 de la Audiencia Territorial de Oviedo. 

El articu

«1. El número total de oficinas de farmacia para la dispensación al público de especialidades farmacéuticas en cada municipio no podrá exceder de una por cada 4.000 habitantes, salvo cuando concurra alguna de las circunstancias siguientes:

b) Cuando la que se pretenda instalar vaya a atender un núcleo de, al menos, dos mil habitantes.»

Una interpretación «mesetaria» del precepto, no infrecuente, lleva consigo la negación de la existencia de núcleo de población cuando ésta se encuentra diseminada y no constituye un núcleo compacto. Afortunadamente el Tribunal Supremo ha sabido intrepretarlo siendo sensible a la realidad sociogeográfica de asentamientos poblacionales como el gallego. Así, en STS de 22 de mayo de 1984 (Az. 3116) (7) se afirma:

«El concepto de "núcleo" tanto debe entenderse como un conjunto de edificaciones contiguas unas otras, como dispersas, si no obstante, forman parte de un mismo sector, participando de la necesidad de unos mismos servicios, pues, como se razona en esta sentencia, los inconvenientes inherentes a una población dispersa no deben verse agravados con criterios como los propugnados por el Consejo General apelante, manteniéndolos más alejados de los establecimientos farmacéuticos que han de estarlo al abrirse una nueva oficina de farmacia dentro del propio sector.»

Y la STS de 4 de marzo de 1985 (Az. 1484) desarrolla y matiza la anterior afirmación:

«La expresión núcleo de población que se utiliza en la norma, hay que interpretarla no el sentido material o físico de conjunto de edificaciones aglutinada sin solución de continuidad, sino de un grupo de personas a las que deba extenderse la zona de influencia de la oficina de farmacia que se pretende abrir, aunque éstas se encuentren diseminadas e incluso en lugar de difícil acceso, pues de lo que se trata es de que las mismas tengan la posibilidad de valerse del servicio público farmacéutico, ya que sería absurdo y

(7) El supuesto se refiere al Puerto de Cabo de Cruz (Boiro) y resulta muy característico. 
por tanto rechazable, el que tales personas no sean tenidas en cuenta a la hora de conformar la cifra de habitantes que legitiman la apertura de una nueva farmacia» (8).

Algo análogo sucede con el artículo 4 del Reglamento de Actividades molestas, insalubre, nocivas y peligrosas que se refiere al «núcleo más próximo de población agrupada» en relación a las distancias. Los ejemplos podrían multiplicarse (paradas de taxis en el término municipal, instalaciones telefónicas, suministro de energía eléctrica, etc.) (9).

\section{LAS LIMITACIONES DE LA PROPIEDAD EN LAS CARRETERAS NO ESTATALES}

Sobre la base del artículo 148.1.15 CE la Comunidad Autónoma de Galicia, en virtud del artículo 27.8 EAG goza de competencia exclusiva en materia de carreteras no incorporadas a la red del Estado y cuyo itinerario se desarolla íntegramente en el territorio de la Comunidad Autónoma. Por ello, la potestad legislativa de la Comunidad Autónoma se extiende a regular esta materia, para lo cual es necesario modificar determinados preceptos de la ley de Carreteras de 19 de diciembre de 1974. Así, en la exposición de motivos de la Ley 6/1983, de 22 de junio, de limitaciones de la propiedad en las carreteras no estatales, puede encontrarse esta orientación innovadora de la ley estatal de 1964 (10).

Pero, es más, la ley de 1974 no tenía en cuenta las peculiaridades circunstancias que concurren en la Comunidad Autónoma Gallega (11), lo cual, unido a la asunción de competencias exclusi-

(8) El mismo criterio se reitera en STS. de 4 de junio de 1984 (Az. 3406) («este Tribunal insiste, una vez más... que no cabe entender como una agrupación o núcleo de viviendas formando un conjunto homogéneo y físicamente delimitado»); de 4 de marzo de 1985 ( $A z$. 1484), de 22 de septiembre de 1982 (Az 5478), de 17 de mayo de 1984 (Az. 3141 ).

(9) De pasada, la Audiencia Territorial de La Coruña (en STS. de 18 de diciembre de 1979 , Az. 4213), aunque correctamente en cuanto a la resolución del caso controvertido, habla de la "indebida equiparación» del concepto de localidad como sinónimo de «lugar», "parroquia» o «núcleo de población»-al interpretar el art. 15 del Reglamento de Servicios Urbanos de Transportes de Automóviles Ligeros, ya que se está empadronado en municipios. Ahora bien, que sea irrelevante el dato de vivir en el lugar donde se fija la parada, siendo lo definitivo el Municipio quizá suponga una concepción foránea de lo que es el asentamiento de la población gallega.

(10) La Ley de Carreteras de 19 de diciembre de 1964 ha quedado desfasada en muchos aspectos, en parte debido a un planteamiento inicial que trataba simplemente de actualizar la normativa fragmentaria $y$ dispersa existente en la época.

(11) Así, como señala acertadamente la exposición de motivos de esta ley, «no es posible dar el mismo tratamiento a un territorio con 31.000 núcleos de población, el 50 por 100 de los núcleos españoles, situados a lo largo de sus vías de comunicación, que a otros cuyas características son radicalmente distintas)). 
vas, también en materia de ordenación del territorio y urbanismo, posibilitan la adopción de medidas de auténtico interés para Galicia.

De todas formas, esta ley, como dice su exposición de motivos, no constituye más que un punto de referencia necesario que debe continuarse con una Ley de Carreteras de la Comunidad Autónoma (12).

La Ley 5/1983 tiene cinco artículos, siendo su contenido esencial, el siguiente:

a) Su ámbito de operatividad se extiende a todas las carreteras cuyo itinerario discurra por el territorio de la Comunidad Autónoma salvo las incorporadas a la red del Estado (art. 1).

b) Se establecen tres redes de carreteras, independiente de su titularidad, cuya determinación se efectuará a través de la futura ley del Plan de Carreteras:

- Red primaria.

- Red secundaria.

- Red terciaria.

c) Se entenderá como zona de circulación de la carretera la constituida por la calzada y arcenes de la misma.

d) La zona de dominio público, según el artículo 3.2, está constituida por los terrenos ocupados por ésta, sus elementos funcionales y una franja de terreno de dos metros de anchura, a cada lado de aquélla, medidos en horizontal y perpendicularmente al eje de la misma, desde la arista exterior de la explanación.

e) La zona de servidumbre de la carretera consistirá en dos franjas de terreno a ambos lados de la misma, delimitada interiormente por la zona de dominio público definida anterior y exteriormente por dos líneas paralelas al límite exterior de dicha zona, a una distancia de cuatro metros, medidos en horizontal y perpendicularmente al eje de la carretera.

f) $Y$, en la red primaria, la línea de edificación se situará a 15,50 metros del eje de trazado de la calzada más próxima, medidos en horizontal a partir del citado eje y perpendicularmente al mismo. En las redes secundarias y terciarias, esta distancia será de 13,50 metros y 10 metros, respectivamente.

Se trata, pues, de una ley dictada para regular un aspecto puntual como es el de establecer las líneas de edificación, porque

(12) En estos momentos se encuentra en el Parlamento Gallego el proyecto de Plan de Carreteras para Galicia; Plan que clasifica en tres redes las carreteras no incorporadas a la del Estado y cuyo recorrido discurre por territorio gallego. 
las determinaciones de la legislación estatal resultan de difícil aplicación en la realidad gallega, debido al peculiar asentamiento de la población.

Se produce, pues, una tensión entre principios técnicos y realidad social que requiere un punto de equilibrio no siempre fácil de encontrar. 